\title{
Phenological Development-Yield Relationships in Durum Wheat Cultivars under Late-Season High-Temperature Stress in a Semiarid Environment
}

\author{
Ghazi N. Al-Karaki \\ Faculty of Agriculture, Jordan University of Science and Technology, Irbid 22110, Jordan \\ Correspondence should be addressed to Ghazi N. Al-Karaki, gkaraki@just.edu.jo
}

Received 29 August 2011; Accepted 9 October 2011

Academic Editors: M. Diaz Ravina and Y. Yan

Copyright (C) 2012 Ghazi N. Al-Karaki. This is an open access article distributed under the Creative Commons Attribution License, which permits unrestricted use, distribution, and reproduction in any medium, provided the original work is properly cited.

\begin{abstract}
A field study was carried out under rainfed conditions during the growing season 2008/2009 in Maru (Northern Jordan) to evaluate the phenological variation using heat-accumulated system and its relation with yield in sixteen durum wheat genotypes. Grain yield was negatively correlated with growing degree days (GDDs) to maturity, while positively correlated with GDD to heading. Increasing GDD to heading resulted in higher grain yield, while increasing grain fill duration had little effect. Rapid grain fill rate was positively correlated with grain weight and negatively correlated with grain fill duration. Waha-1, Omrabi-5, and Massara-1 genotypes had the highest grain yields among genotypes studied. These three genotypes tended to have relatively longer preheading periods with early maturity. The results of this study indicate that Mediterranean-adapted cultivars would have long preheading periods, followed by short periods and high rates of grain fill and mature early to avoid late-season drought and high-temperature stress and to attain high yields. Therefore, it is recommended for the development of high yielding wheat cultivars adapted to semiarid environments to select the genotypes with early maturity and a relatively long time to heading.
\end{abstract}

\section{Introduction}

Durum wheat (Triticum turgidum L. cv. durum) is an important cereal crop traditionally grown under rainfed conditions in the Mediterranean region (e.g., Jordan) and other marginal environments of the semiarid tropics. Drought and high temperature stress at the terminal of growing season usually constrain crop yield potential as these stresses coincide with the grain filling period in these regions [1-4]. The problem of heat stress is likely to become even worse in the future under global environmental change which has become one of the greatest challenges that humanity faces today. The latest Assessment Report of the Intergovernmental Panel on Climate Change projects that the drought occurrence will increase especially for arid and semiarid regions and the global average temperatures in 2100 will be 1.8 to $4.0^{\circ} \mathrm{C}$ higher than the 1980-2000 average [5]. However, even when water is not a limiting factor (e.g., supplied by irrigation), lower yields were obtained in dry and semidry environments as a result of heat stress that occurs during anthesis and grain filling periods $[2,6]$, which imposes negative effects on wheat and other crops production. These stress factors have negative influences on the movement of photosynthetic products to the developing grains and inhibited starch synthesis; thus, it causes lower grain weight which might result in lower grain yields [7]. For healthy wheat growth and a good yield, the range of the optimum temperatures was 18 to $24^{\circ} \mathrm{C}$. Temperatures above 28 to $32^{\circ} \mathrm{C}$ for short periods (e.g., 5 to 6 days) found to cause about $20 \%$ or more wheat yield losses [8]. Acevedo et al. [9] have also reported that every $1^{\circ} \mathrm{C}$ increase over 17 to $24^{\circ} \mathrm{C}$ in average temperature during wheat grain filling causes four percent yield reduction in grain weight from yield components.

Drought and heat stress are important environmental factors affecting the rate of plant growth and development [10-13]. Under these stress factors, the wheat crop completes its life cycle much faster than under normal conditions [14]; consequently, crop growth stages will have a short duration, 
with fewer days to accumulate assimilates during life cycle, and hence the production of biomass is reduced $[15,16]$.

Plants have a definite temperature requirement before they attain certain phenological stages. The accumulative heat units and system was adopted for determining the dates to flowering/heading and maturity of different field crops [13, 17-20]. However, different phenological stages differ in their sensitivity to drought and high temperature stress, and this depends on plant species and genotype as there are great inter and intraspecific variations $[12,21]$. It is high time to develop high yielding wheat varieties that are suitable to different stressful conditions. Future increases in the potential yield of wheat will require an increase in the photosynthetic area in early growth stages, in order to augment the incident radiation intercepted by the crop and the total biomass produced [22]. Moreover, crop cultivars can fill their seeds/grains quickly and may have an advantage in environments with prevailing of late-season drought and heat stress during seed/grain filling periods [18, 23-25]. So, they can avoid the prematurely stop grain growth and the acceleration of physiological maturity in late maturing cultivars under stress environmental conditions such as high temperature.

Some stress indicators or selection criteria, such as stay green leaves at or after physiological maturity, have been proposed as a way to identify genotypes with better stress tolerance like late-season drought and heat stress. Some researchers related between staying green plants and heat tolerance [25-28]. It was stressed that healthy stay-green plants are more producible for grain yield $[29,30]$. Kumar et al. [28] have reported that stay green or delayed senescence is considered to play a crucial role in grain development in wheat when assimilates are limited, and stay green cultivars are well adapted to drought and heat-stressed conditions.

The objectives of this study are to evaluate the phenological variation of sixteen durum wheat genotypes and its relation with grain yield and to identify the genotypes adapted to late-season high-temperature stress and drought conditions in a semiarid location in Northern Jordan.

\section{Materials and Methods}

A field experiment was carried out during the 2008/2009 agricultural growing season under rainfed conditions in a semiarid location $\left(34^{\circ} 40^{\prime} \mathrm{N}, 590 \mathrm{~m}\right.$ elevation), in Maru, Northern Jordan. The mean annual rainfall at this location is $370 \mathrm{~mm}$. This location typically experiences moderate drought and high-temperature stress during the postanthesis and grain-filling periods. The soil at the location is silty clay (fine montmorillonitic, thermic, entic chromoxeret) with low levels of organic matter (1.2\%) and a pH of 7.9. At the beginning of the season, the experimental area was prepared with a moldboard plow followed by disking.

Sixteen durum wheat genotypes, consisting of one Jordanian variety (Hourani-27), and 15 genotypes provided by the International Center for Agricultural Research in the Dry Areas (ICARDA), Aleppo, Syria, which were brought from different Mediterranean countries (Omguer5, Genil-3, Stork, Korifla, Omrabi-5, Waha-1, Stojocri-3,
Massara-1, Omsnima-1, Lagost-3, Heina, Ombar, Gersabil2, Moulsabil-2, and Zeina-3) were used in this study. These genotypes represent a wide range of genetic variability for physiological and agronomical traits [31]. Planting was carried out during the second week of November. The experimental design was a randomized complete block with three replicates. Experimental plots were $2.1 \mathrm{~m} \times 5 \mathrm{~m}$ with six rows spaced $0.35 \mathrm{~m}$ apart and with $10 \mathrm{~cm}$ between plants. Fertilizer was hand broadcasted prior to seeding at a rate of $50 \mathrm{~kg} \mathrm{ha}^{-1}$ of nitrogen (as urea) and $30 \mathrm{~kg} \mathrm{ha}^{-1}$ of $\mathrm{P}_{2} \mathrm{O}_{5}$ (as triple superphosphate). Weeds were removed manually as needed.

During the growth period, data was recorded on days to heading (when approximately $50 \%$ of spikes had completely emerged from the boot) and days to physiological maturity (when approximately 60\% of spikes had lost all green color). For these and all other phenological measurements, plant development was assessed using growing degree days (GDDs), with a base temperature of $0^{\circ} \mathrm{C}$ [32]. Daily GDDs were calculated as Daily GDD $=\left[\left(T_{\max }+T_{\min }\right) / 2\right]-T_{\mathrm{b}}$, where $T_{\max }$ and $T_{\min }$ are maximum and minimum temperatures and $T_{\mathrm{b}}=$ minimum temperature at which growth ceases (the base temperature). Accumulated GDDs were calculated by summation of daily GDD of each developmental stage.

Beginning one week after heading, 50 spikes in one of the center four rows in all replicates of a given genotype emerged from the boot were tagged with colored yarn. Approximately 10 days later, five tagged spikes were sampled randomly from each plot at approximately weekly intervals until harvesting. Sampled spikes were dried immediately in air-forced drying oven at $60^{\circ} \mathrm{C}$ for $48 \mathrm{~h}$ and then threshed. The number and weight of grains out of sampled spikes at each interval were recorded. The average grain weight of each five-spike sample was calculated as the weight of grains in each sample divided by the number of grains.

Grain fill duration was calculated for each plot as accumulated GDD from heading to physiological maturity. Grain fill rate was estimated by fitting a linear regression equation to the grain dry weights per GDD, at different sampling dates for each plot, after the obviously nonlinear points were eliminated [33]. Duration of life cycle was estimated as accumulated GDD from planting to physiological maturity.

The stay-green rating was visually scored at or soon after physiological maturity according to the procedures described by Xu et al. [27]. Scoring was done on a 1-5 scale based on the proportion of leaf area of normal-sized leaves which had prematurely senesced and died. A rating of 1, 2, 3, and 4 indicated no leaf death, approximately 40,60 , and $80 \%$ of mature leaf area are dead, respectively, while 5 indicated $100 \%$ plant (leaves and stem) death.

At physiological maturity stage, number of spikes were counted on the basis of square meter in the three middle rows. Ten spikes from each plot were sampled randomly, sundried, and threshed for determination of grains number per spike. The threshed grains were then added to the total for determination of grain yield.

At harvest time (during June), heads from plants in the three middle rows of each plot (excluding the row out of which spikes were sampled) were harvested manually, 
sun-dried for 2 weeks, and threshed. Grains were weighed for determination of grain yield. Grain weight (200 grain sample) was determined from the grain yield samples.

Analyses of variance (ANOVA), correlation coefficients, and least significant differences (LSD) were computed using the MSTAT-C computer program [34].

\section{Results and Discussion}

The total rainfall received at the location of study during 2008/2009 growth season was $378 \mathrm{~mm}$ which was similar to that of the average of rainfall in the area for the last 5 years which was $370 \mathrm{~mm}$. However, the rainfall distribution for the growth season was different than that for the average of the last 5 years when most of rain fallen during the growth season was received in February and March (Figure 1). Favorable moisture conditions combined with low temperatures prevailed during the vegetative stages (November-February), and stressed moisture conditions with high temperatures prevailed during the reproductive stages (April-June) (Figures 1 and 2). Low to moderate maximum temperatures prevailed during the beginning of season and continued until the third week of March (Figure 2). Linear increase in temperature started by the end of March and reached about $30^{\circ} \mathrm{C}$ by the third week of May. High temperatures beyond $30^{\circ} \mathrm{C}$ persisted in June. Overall, high temperatures in the range of 30 to $34^{\circ} \mathrm{C}$ prevailed from second week of May to the second week of June.

The timing of heading and maturity are among the major traits that related to the adaptation of wheat cultivars under prevalent field conditions in particular areas. Under normal environmental conditions, early heading and late maturity, for example, permits a long grain-filling period during which photosynthetic components remain green, improving grain filling because the contribution of postanthesis assimilates is important to grain yields in cereals $[35,36]$. However, high-temperature stress was found to induce modifications in plants through altering the pattern of plant development [15]. These responses may differ from one phenological stage to another. Vulnerability of species and cultivars to high temperatures may vary with the stage of plant development but all vegetative and reproductive stages are affected by heat stress to some extent $[15,24]$. In this study, significant differences existed among studied cultivars for GDD of heading and maturity traits. Omsnima-1 and Moulsabil2 were among the earliest-heading genotypes and latestmaturing studied genotypes (Table 1). Therefore, they have the longer grain fill periods (1311 and 1319 GDD for Omsnima-1 and Moulsabil, resp.) than the other genotypes studied (Table 1). Genotypes of similar or somewhat early heading (Omguer-5, Massara-1, Lagost-3, and Zeina-3), on the other hand, tended to have shorter grain fill duration (Table 1). Massara-1, for example, spent 14 GDD less than Omsnima-1 in the pre-heading stage, but 172 GDD less than Omsnima-1 in the grain fill stage. Omsnima-1 also had the lowest grain yield of all genotypes studied.

Wheat adapted to environments characterized by lateseason rise in temperature has been reported to relatively mature early to avoid heat stress at the critical stages of

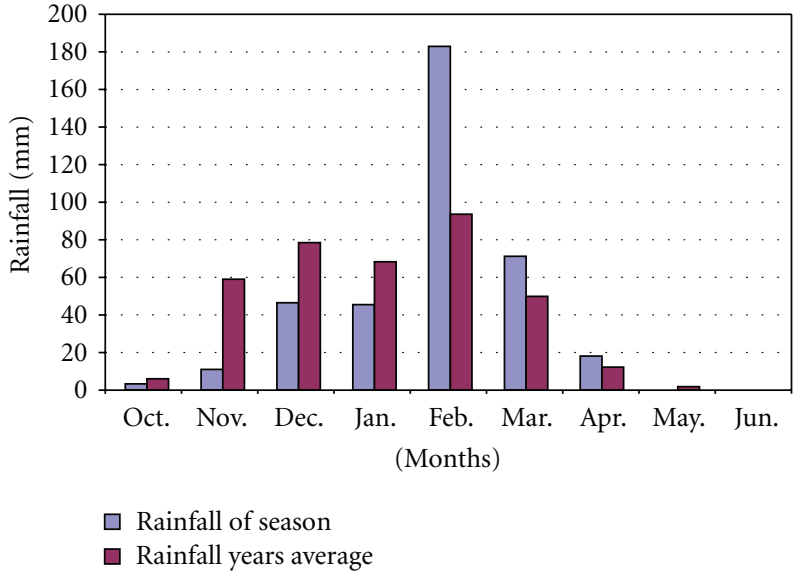

Figure 1: Rainfall during the growing season 2008/2009 and the rainfall for the last 5 years at Maru, Northern Jordan.

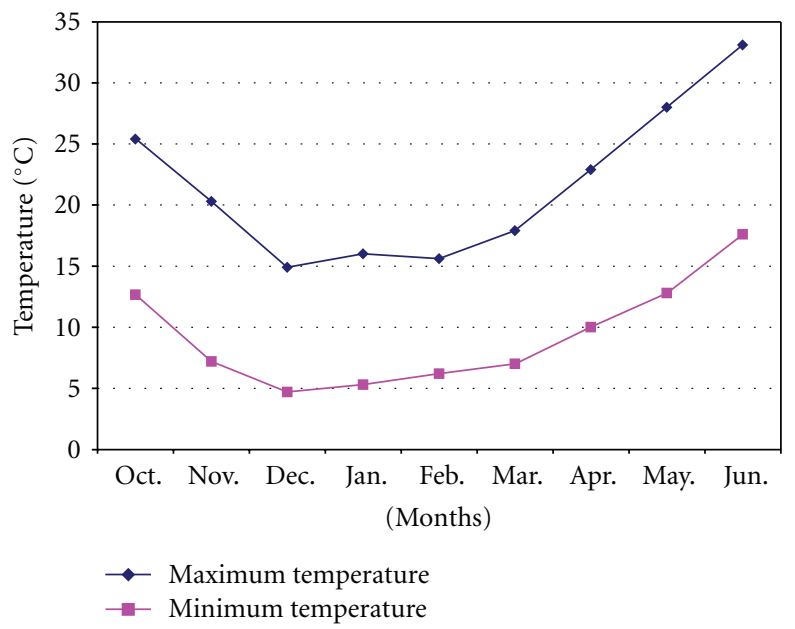

FIgure 2: Maximum and minimum temperatures during the experimental period during the 2008/2009 season at Maru, Northern Jordan.

grain filling [37]. Among the sixteen genotypes studied, the genotypes Waha-1, Omrabi-5, and Massara-1 had the highest grain yields $\left(4786,4646\right.$, and $4526 \mathrm{~kg} \mathrm{ha}^{-1}$ for Waha1 Omrabi-5, and Massara-1, resp.) under the prevailing environmental conditions of the region. These three genotypes tended to have longer pre-heading periods and early maturity (Table 1). It can be said that these three genotypes have more tolerance to late-season drought and hightemperature stress than other genotypes studied. However, the local genotype "Hourani-27" tended to have the longest pre-heading period and relatively high grain yield. These results suggest that the higher yield potential of genotypes correlates with and may be due in part to longer pre-heading periods relative to grain fill periods and relatively early maturing. Àlvaro et al. [38] reported that high grain yield in durum wheat was associated with an extended period of the pre-heading stage. This is supported by results obtained by Metzger et al. [39] who found that in genotypes those 
TABLe 1: Phenological traits ${ }^{1}$, grain filling rate, grain weight, and grain yield of durum wheat genotypes grown at Maru location.

\begin{tabular}{|c|c|c|c|c|c|c|c|c|}
\hline Genotype & PL to HD & $\begin{array}{c}\text { PL to PM } \\
\text { GDD }\end{array}$ & GF duration & $\begin{array}{c}\text { GF rate } \\
\text { mg/100 GDD }\end{array}$ & Spikes $/ \mathrm{m}^{2}$ & Grains/spike & $\begin{array}{l}\text { Grain weight } \\
\text { mg/seed }\end{array}$ & $\begin{array}{c}\text { Grain yield } \\
\text { kg/ha }\end{array}$ \\
\hline Hourani-27 & 1230 & 2363 & 1133 & 3.75 & 215 & 42.3 & 42.5 & 3866 \\
\hline Omguer-5 & 1106 & 2396 & 1290 & 3.91 & 197 & 33.7 & 48.5 & 3213 \\
\hline Genil-3 & 1206 & 2389 & 1183 & 4.18 & 204 & 37.6 & 49.5 & 3800 \\
\hline Stork & 1118 & 2396 & 1278 & 4.27 & 177 & 32.6 & 54.5 & 3333 \\
\hline Korifla & 1156 & 2363 & 1207 & 3.19 & 191 & 38.1 & 38.6 & 2813 \\
\hline Omrabi-5 & 1218 & 2361 & 1143 & 3.98 & 316 & 32.3 & 45.5 & 4646 \\
\hline Waha-1 & 1188 & 2302 & 1114 & 3.57 & 318 & 37.1 & 40.5 & 4786 \\
\hline Stojocri-3 & 1143 & 2365 & 1222 & 4.44 & 154 & 33.7 & 55.5 & 2887 \\
\hline Massara-1 & 1166 & 2305 & 1139 & 4.11 & 275 & 32.2 & 51.0 & 4526 \\
\hline Omsnima-1 & 1180 & 2401 & 1311 & 3.44 & 170 & 33.9 & 45.1 & 2600 \\
\hline Lagost-3 & 1106 & 2396 & 1290 & 4.57 & 183 & 30.1 & 59.0 & 3246 \\
\hline Heina & 1205 & 2387 & 1182 & 4.02 & 180 & 35.3 & 47.5 & 3013 \\
\hline Ombar & 1094 & 2361 & 1267 & 4.14 & 191 & 34.8 & 52.5 & 3694 \\
\hline Gersabil-2 & 1081 & 2336 & 1255 & 3.9 & 175 & 36.2 & 49.0 & 3113 \\
\hline Moulsabil-2 & 1106 & 2425 & 1319 & 3.71 & 169 & 38.1 & 49.0 & 3166 \\
\hline Zeina-3 & 1095 & 2361 & 1266 & 3.83 & 196 & 36.2 & 48.5 & 3440 \\
\hline LSD (0.05) & 32 & 43 & 47 & 0.6 & 34 & 3.6 & 2.5 & 492 \\
\hline
\end{tabular}

${ }^{1}$ PL: planting; HD: heading; PM: physiological maturity; GF: grain fill.

with shorter grain-fill periods and longer vegetative periods tended to be higher yielding.

The genotypes with longer pre-heading periods and early maturity might have two advantages over the early-heading and late-maturity genotypes. First, when air temperatures are lower and soil moisture is available which is generally more favorable for more tiller number per plant and subsequently higher spike density. Shezad et al. [40] reported that yield components were assumed to develop sequentially, with earlier-forming components (e.g., tillers) influencing those developed later (e.g., spikes). Late maturing with long grain filling period genotypes were assumed to influence only kernel weight, because spike number per plant and kernel number per spike were determined before the initiation of grain fill. In this study, higher number of spikes $\mathrm{m}^{-2}$ resulted in higher grain yields in the genotypes Waha and Omrabi-5 which had the highest number of spikes $\mathrm{m}^{-2}$ and highest yields among studied genotypes (Table 1). The second advantage of long pre-heading period and early maturity is that a greater fraction of grain filling occurs when air temperatures are generally favorable for wheat. High temperature during the grain filling period has been reported to accelerate senescence and cause yield reductions [41].

Across all cultivars, grain fill duration ranged from a low of 1133 GDD in Hourani-27 to a high of 1319 GDD in Moulsabil-2. The association between grain fill duration and GDD to physiological maturity was strong (Table 2). For example, both Hourani-27 and Moulsabil-2 representing extremes of grain fill duration were relatively early maturing and late maturing for Hourani-27 and Moulsabil-2, respectively. Grain filling period is under genetic control and can be used for indirect yield selection in these genotypes. This is supported by other researcher's findings for wheat [24, 42].
Grain fill rate ranged from a low of $3.19 \mathrm{mg}(100 \mathrm{GDD})^{-1}$ for Korifla to a high of $4.57 \mathrm{mg}(100 \mathrm{GDD})^{-1}$ for Lagost-3 (Table 1). The genotypes of relatively slowest grain-fill rates are relatively late maturing and thus not well adapted to Mediterranean semiarid environments. Wheat genotypes that can fill their grain quickly may have an advantage in environments where crop plants experience moisture and high-temperature stress during the grain filling periods [23]. So, to avoid the stress condition, they complete their life cycle earlier.

Variation in grain yield among genotypes studied was relatively high (Table 1). However, a part of this variation is usually due to the environment [39]. Grain yield ranged from a low of $2600 \mathrm{~kg} \mathrm{ha}^{-1}$ for Omsnima-1 to a high of $4786 \mathrm{~kg} \mathrm{ha}^{-1}$ for Waha-1 (Table 1). The highest yielding genotypes were those of short-medium filling period, a medium-late GDD to heading, and early-medium GDDs to maturity. However, grain yield was low when the filling period was relatively long, whether GDD to heading or to maturity were medium or late. This suggests that proper balancing of these developmental traits may facilitate a more desirable combination which results in higher grain yields.

Correlations among the grain yield, grain fill rate, spikes number $\mathrm{m}^{-2}$, grains number spike ${ }^{-1}$, and phenological development characters are presented in Table 2. Grain yield was strongly associated with spikes $\mathrm{m}^{-2}\left(0.92^{* *}\right)$ but not with grains $\mathrm{spike}^{-1}$. Rapid grain fill rate was positively correlated with GDD to heading (0.23) but was negatively correlated with GDD to physiological maturity $\left(-0.25^{*}\right)$. Wong and Baker [42] reported positive correlations between days to maturity and days to heading and negative correlations between days to maturity and filling period in wheat cultivars. In this study, the length of 
TABLE 2: Correlation coefficients among different characters ${ }^{1}$.

\begin{tabular}{|c|c|c|c|c|c|c|c|}
\hline Character & PL to HD & $\begin{array}{r}\text { PL to PM } \\
\text { GDD }\end{array}$ & GF duration & $\begin{array}{c}\text { GF rate } \\
\mathrm{mg} / 100 \mathrm{GDD}\end{array}$ & $\begin{array}{l}\text { Grain wt } \\
\text { mg/grain }\end{array}$ & $\begin{array}{c}\text { Spikes } / \mathrm{m}^{2} \\
\text { No. }\end{array}$ & $\begin{array}{c}\text { Grains/spike } \\
\text { No. }\end{array}$ \\
\hline Grain yield & $0.20^{*}$ & $-0.39^{*}$ & NS & NS & $-0.21^{*}$ & $0.92^{*}$ & NS \\
\hline PL to HD & & -0.17 & $-0.55^{* *}$ & 0.23 & NS & $0.49^{*}$ & 0.30 \\
\hline PL to PM & & & $0.49^{* *}$ & $-0.25^{*}$ & NS & $-0.65^{* *}$ & NS \\
\hline GF duration & & & & $-0.29^{*}$ & $0.42^{*}$ & $-0.74^{* *}$ & -0.28 \\
\hline GF rate & & & & & $0.92^{* *}$ & -0.15 & $-0.57^{*}$ \\
\hline Spikes $/ \mathrm{m}^{2}$ & & & & & -0.41 & & NS \\
\hline
\end{tabular}

the grain fill period was positively associated with time to physiological maturity $\left(0.49^{* *}\right)$, since these periods are not independent of each other. No significant correlations were found between grain weight and GDD to heading or GDD to physiological maturity. Grain fill rate and grain fill duration were negatively correlated $\left(-0.29^{*}\right)$, indicating that environmental or genetic conditions that resulted in rapid grain fill rate were associated with short grain fill duration. This agrees with results obtained by Bruckner and Frohberg [43] working with spring wheat. Grain fill rate was positively correlated with high grain weight. Thus, higher grain fill rate resulted in higher grain weight. Similar observations were obtained by Nass and Reiser [44]. Higher grain weight, however, would not result in significantly higher grain yield because of the lack of relationship between grain weight and grain yield [45]. Grain yield was negatively and significantly correlated with GDD to maturity duration but positively and significantly correlated with GDD to heading (Table 2), however, no significant correlations between grain yields with grain fill duration or rate. Selection for shorter grain fill duration, while maintaining duration of the preheading period, could therefore provide a means to shorten time to maturity without reducing grain yield, through avoiding terminal drought and high -temperature stress. Thus, lengthening the pre-heading period of development would provide a better means of increasing grain yield than increasing the length of the grain fill period. Ney et al. [46] reported that when pea plants were exposed to drought stress during the late seed filling period, the seed growth rate was not affected due to maintenance filling by mobilizing reserved accumulated during the preflowering stage.

It has been reported that staying green of plants under stress conditions is considered an important trait for adaptation to drought and heat-stressed conditions. In this study, stay-green scorings of the genotypes at or after physiological maturity showed high variation (Figure 3 ). In this connection, Omguer-5, Korifla, and Omsnima-1 had the highest scores while Massara-1, Omrabi-5, Stork, Genil-5, and Hourani-27 had the lowest scorings of stay-green. Low scores means that the leaves/plants stay-green for longer periods at or after physiological maturity. Bahar et al. [47] found significant differences between bread wheat cultivars for stay green duration under drought and heat stress conditions. Long stay green duration would be beneficial that allows plants to retain their leaves actively photosynthetic under stress conditions [1].

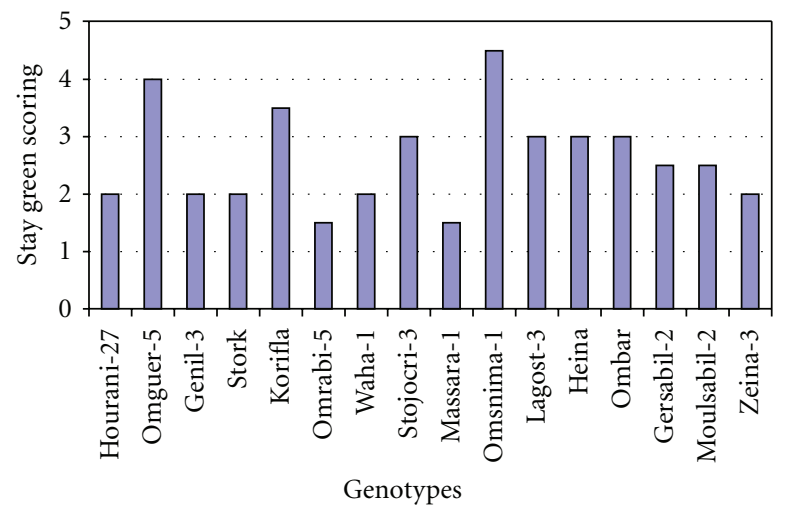

FIGURE 3: Variations for stay-green scoring of 16 durum wheat genotypes grown during the 2008/2009 season at Maru, Northern Jordan.

\section{Conclusions}

From the above study, the results indicate that variation in length of the pre-heading stage influences grain yield more than variation in length of grain filling. Lengthening the preheading period increased grain yield, but lengthening the grain fill stage did not affect yield. Simultaneously, selection for early maturity and long pre-heading period is recommended in the development of early maturing and high yielding genotypes for the Mediterranean semiarid areas. Waha-1, Omrabi-5, and Massara-1 were the best performing genotypes at late-stage drought and high-temperature stress conditions as they gave the highest grain yields among genotypes studied. Plants of Omrabi-5 genotype showed also to stay green for longer period after physiological maturity.

\section{References}

[1] M. Koç, C. Barutçular, and M. Tiryakioğlu, "Possible heattolerant wheat cultivar improvement through the use of flag leaf gas exchange traits in a Mediterranean environment," Journal of the Science of Food and Agriculture, vol. 88, no. 9, pp. 1638-1647, 2008.

[2] L. F. García del Moral, Y. Rharrabti, D. Villegas, and C. Royo, "Evaluation of grain yield and its components in durum wheat under Mediterranean conditions: an ontogenic approach," Agronomy Journal, vol. 95, no. 2, pp. 266-274, 2003. 
[3] B. Simane, J. M. Peacock, and P. C. Struik, "Differences in developmental plasticity and growth rate among droughtresistant and susceptible cultivars of durum wheat (Triticum turgidum L. var. durum)," Plant and Soil, vol. 157, no. 2, pp. 155-166, 1993.

[4] G. Sarkar, C. K. Srivastava, and P. S. Deshmukh, "Grain growth rate and heat susceptibility index: traits for breeding genotypes tolerant to terminal high temperature stress in bread wheat (Triticum aestivum L.)," Indian Journal of Genetics, vol. 61, no. 3, pp. 209-212, 2001.

[5] IPCC, "The physical science basis. Summary for policymakers," Fourth Assessment Report of the Intergovernmental Panel on Climate Change, 2007.

[6] R. Savin, P. J. Stone, M. E. Nicolas, and I. F. Wardlaw, "Grain growth and malting quality of barley. 2. Effects of temperature regime before heat stress," Australian Journal of Agriculture Research, vol. 48, no. 5, pp. 625-634, 1997.

[7] S. S. Bhullar and C. F. Jenner, "Differential responses to high temperature of starch and nitrogen accumulation in the grain of four cultivars of wheat," Australian Journal of Plant Physiology, vol. 12, pp. 363-375, 1985.

[8] P. J. Stone and M. E. Nicolas, "Wheat cultivars vary widely in their responses of grain yield and quality to short periods of post-anthesis heat stress," Australian Journal of Plant Physiology, vol. 21, pp. 887-900, 1994.

[9] E. Acevedo, M. Nachit, and G. Ortiz-Ferrara, "Effects of heat stress on wheat and possible selection tools for use in breeding for tolerance," in Wheat for the Nontraditional Warm Areas, D. A. Saunders, Ed., pp. 401-421, CIMMYT, Texcoco, Mexico, 1991.

[10] A. E. Hall, Crop Responses to Environment, CRC Press, Boca Raton, Fla, USA, 2001.

[11] K. B. Marcum, "Cell membrane thermostability and wholeplant heat tolerance of Kentucky bluegrass," Crop Science, vol. 38, no. 5, pp. 1214-1218, 1998.

[12] C. J. Howarth, "Genetic improvements of tolerance to high temperature," in Abiotic Stresses: Plant Resistance Through Breeding and Molecular Approaches, M. Ashraf and P. J. C. Harris, Eds., Howarth Press, New York, NY, USA, 2005.

[13] S. Sikder, "Accumulated heat unit and phenology of wheat cultivars as influenced by late sowing heat stress condition," Journal of Agriculture and Rural Development, vol. 7, pp. 5764, 2009.

[14] R. A. Fischer, "Physiological limitations to producing wheat in semi-tropical and tropical environments and possible criteria," in Wheats for More Tropical Environments, R. C. Villareal and A. R. Klatt, Eds., pp. 209-230, CIMMYT, Texcoco, Mexico, 1985.

[15] A. Wahid, S. Gelani, M. Ashraf, and M. R. Foolad, "Heat tolerance in plants: an overview," Environmental and Experimental Botany, vol. 61, no. 3, pp. 199-223, 2007.

[16] R. A. Fischer and R. Maurer, "Crop temperature modification and yield potential in a dwarf spring wheat," Crop Science, vol. 16, pp. 855-859, 1976.

[17] J. F. Bierhuizen, "The effect of temperature on plant growth, development and yield," in Plant Response to Climatic Factors, pp. 89-98, Proceedings of the Uppsala symposium, Paris, France, 1973.

[18] G. N. Al-Karaki, "Phenological development-yield relationships in dry pea in semiarid Mediterranean conditions," Journal of Agronomy and Crop Science, vol. 182, no. 2, pp. 7378, 1999 .
[19] R. P. Rajput, M. R. Deshmukh, and V. K. Paradkar, "Accumulated heat unit and phenology relationships in wheat (Triticum aestivum L) as influenced by planting dates under late sown conditions," Journal of Agronomy and Crop Science, vol. 159, pp. 345-348, 1987.

[20] O. P. Bishnoi, S. Singh, and R. Niwas, "Effect of temperature on phenological development of wheat (Triticum aestivum L.) crop in different row orientations," The Indian Journal of Agricultural Sciences, vol. 65, pp. 211-214, 1995.

[21] B. Wollenweber, J. R. Porter, and J. Schellberg, "Lack of interaction between extreme high-temperature events at vegetative and reproductive growth stages in wheat," Journal of Agronomy and Crop Science, vol. 189, no. 3, pp. 142-150, 2003.

[22] G. A. Slafer and E. M. Whitewchurch, "Manipulating wheat development to improve adaptation," in Application of Physiology in Wheat Breeding, M. P. Reynolds, J. I. Ortiz-Monasterio, and A. M. C. Nab, Eds., pp. 160-170, CIMMYT, Texcoco, Mexico, 2001.

[23] B. R. Whan, G. P. Carlton, and W. K. Anderson, "Potential for increasing rate of grain growth in spring wheat. I. Identification of genetic improvements," Australian Journal of Agricultural Research, vol. 47, no. 1, pp. 17-31, 1996.

[24] H. Tewolde, C. J. Fernandez, and C. A. Erickson, "Wheat cultivars adapted to post-heading high temperature stress," Journal of Agronomy and Crop Science, vol. 192, no. 2, pp. 111120, 2006.

[25] V. Bavei, B. Vaezi, M. Abdipour, M. Kamali, and M. Roustaii, "Screening of tolerant spring barleys for terminal heat stress: different importance of yield components in barleys with different ro type," International Journal of Plant Breeding and Genetics, vol. 5, pp. 175-193, 2011.

[26] A. Blum, C. Y. Sullivan, and H. T. Nguyen, "The effect of plant size on wheat response to agents of drought stress. II. Water deficit, heat and ABA," Australian Journal of Plant Physiology, vol. 24, no. 1, pp. 43-48, 1997.

[27] W. Xu, D. T. Rosenow, and H. T. Nguyen, "Stay green trait in grain sorghum: relationship between visual rating and leaf chlorophyll concentration," Plant Breeding, vol. 119, no. 4, pp. 365-367, 2000.

[28] U. Kumar, A. K. Joshi, M. Kumari, R. Paliwal, S. Kumar, and M. S. Röder, "Identification of QTLs for stay green trait in wheat (Triticum aestivum L.) in the 'Chirya 3' $\times$ 'Sonalika' population," Euphytica, vol. 174, no. 3, pp. 437-445, 2010.

[29] M. Ban Bella and G. M. Paulson, "Efficiency of treatments for delaying senescence of wheat leaves: II. Senescence and grain yield under field conditions," Agronomy Journal, vol. 90, pp. 332-338, 1998.

[30] H. Thomas H. and C.M. and C. M. Smart, "Crops that stay green," Annals of Applied Biology, vol. 123, pp. 193-229, 1993.

[31] G. N. Al-Karaki and K. I. Ereifej, "Seed chemical composition as related to seed yield of durum wheat under arid and semiarid Mediterranean environments," in Triticeae III, A. A. Jaradat, Ed., pp. 439-444, Oxford and I.B.H. Publishing, London, UK, 1998.

[32] W. Cao and D. M. Moss, "Temperature effect on leaf emergence and phyllochron in wheat and barley," Crop Science, vol. 29, pp. 1018-1021, 1989.

[33] L. Meckel, D. B. Egli, R. F. Phillips, D. Radcli, and J. E. Leggett, "Effect of moisture stress on seed growth in soybeans," Agronomy Journal, vol. 76, pp. 647-650, 1984.

[34] O. F. Russell, MSTAT-C v.2.1 (A Computer Based Data Analysis Software), Michigan State University, East Lansing, Mich, USA, 1994. 
[35] F. Bidinger, R. B. Musgrave, and R. A. Fischer, "Contribution of stored pre-anthesis assimilate to grain yield in wheat and barley," Nature, vol. 270, no. 5636, pp. 431-433, 1977.

[36] A. C. Sanchez, P. K. Subudhi, D. T. Rosenow, and H. T. Nguyen, "Mapping QTLs associated with drought resistance in sorghum (Sorghum bicolor L. Moench)," Plant Molecular Biology, vol. 48, no. 5-6, pp. 713-726, 2002.

[37] M. Khan, T. Mohammad, F. Subhan, M. Amin, and S. T. Shah, "Agronomic evaluation of different bread wheat (Triticum aestivum L.) genotypes for terminal heat stress," Pakistan Journal of Botany, vol. 39, pp. 2415-2425, 2007.

[38] F. Álvaro, J. Isidro, D. Villegas, L. F. García Del Moral, and C. Royo, "Breeding effects on grain filling, biomass partitioning, and demobilization in Mediterranean durum wheat," Agronomy Journal, vol. 100, no. 2, pp. 361-370, 2008.

[39] D. D. Metzger, S. J. Czaplewski, and D. C. Rasmusson, "Grainfilling duration and yield in spring barley," Crop Science, vol. 24, pp. 1101-1105, 1984.

[40] K. Shezad, J. Bakht, W. Ali Shah, M. Shafi, and N. Jabeen, "Yield and yield components of various wheat cultivars as affected by different sowing dates," Asian Journal of Plant Sciences, vol. 1, no. 5, pp. 522-525, 2002.

[41] K. Al-Khatib and G. M. Paulsen, "Mode of high temperature injury to wheat during grain development," Plant Physiology, vol. 61, pp. 363-368, 1984.

[42] L. S. L. Wong and R. J. Baker, "Selection for time to maturity in spring wheat," Crop Science, vol. 26, pp. 1171-1175, 1989.

[43] P. L. Bruckner and R. C. Frohberg, "Rate and duration of grain fill in spring wheat," Crop Science, vol. 27, pp. 451-455, 1987.

[44] H. G. Nass and B. Reiser, "Grain filling period and grain yield relationships in spring wheat," Canadian Journal of Plant Science, vol. 55, pp. 673-678, 1975.

[45] S. M. Dofing, "Phenological development-yield relationships in spring barley in a subarctic environrnent," Canadian Journal of Plant Science, vol. 751, pp. 93-97, 1995.

[46] B. Ney, C. Duthion, and O. Turc, "Phenological response of pea to water stress during reproductive development," Crop Science, vol. 34, no. 1, pp. 141-146, 1994.

[47] B. Bahar, M. Yildirim, and C. Yucel, "Heat and drought resistance criteria in spring bread wheat (Triticum aestivum L.): morpho-physiological parameters for heat tolerance," Scientific Research and Essays, vol. 6, no. 10, pp. 2212-2220, 2011. 


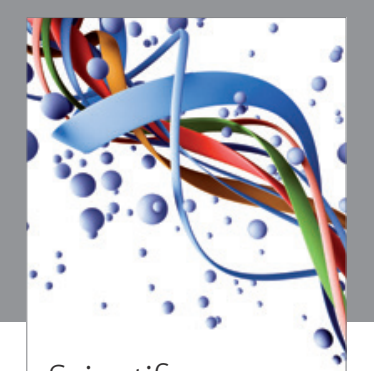

Scientifica
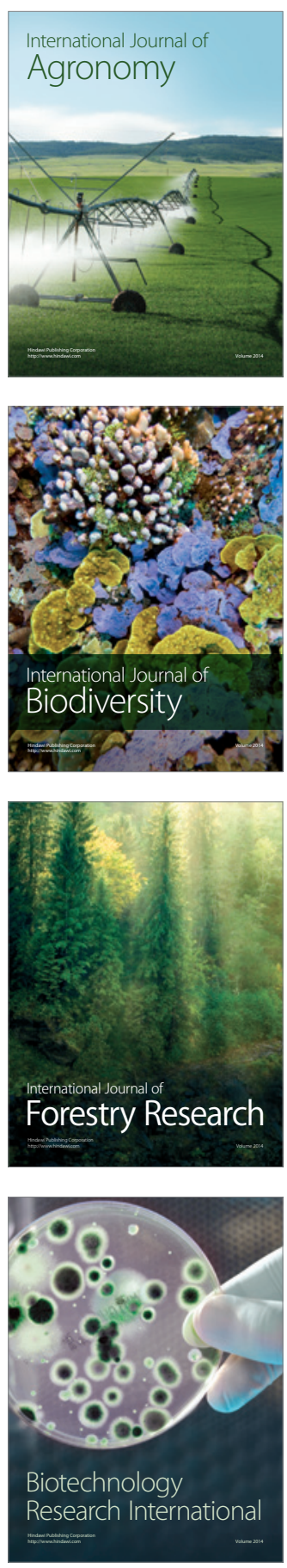
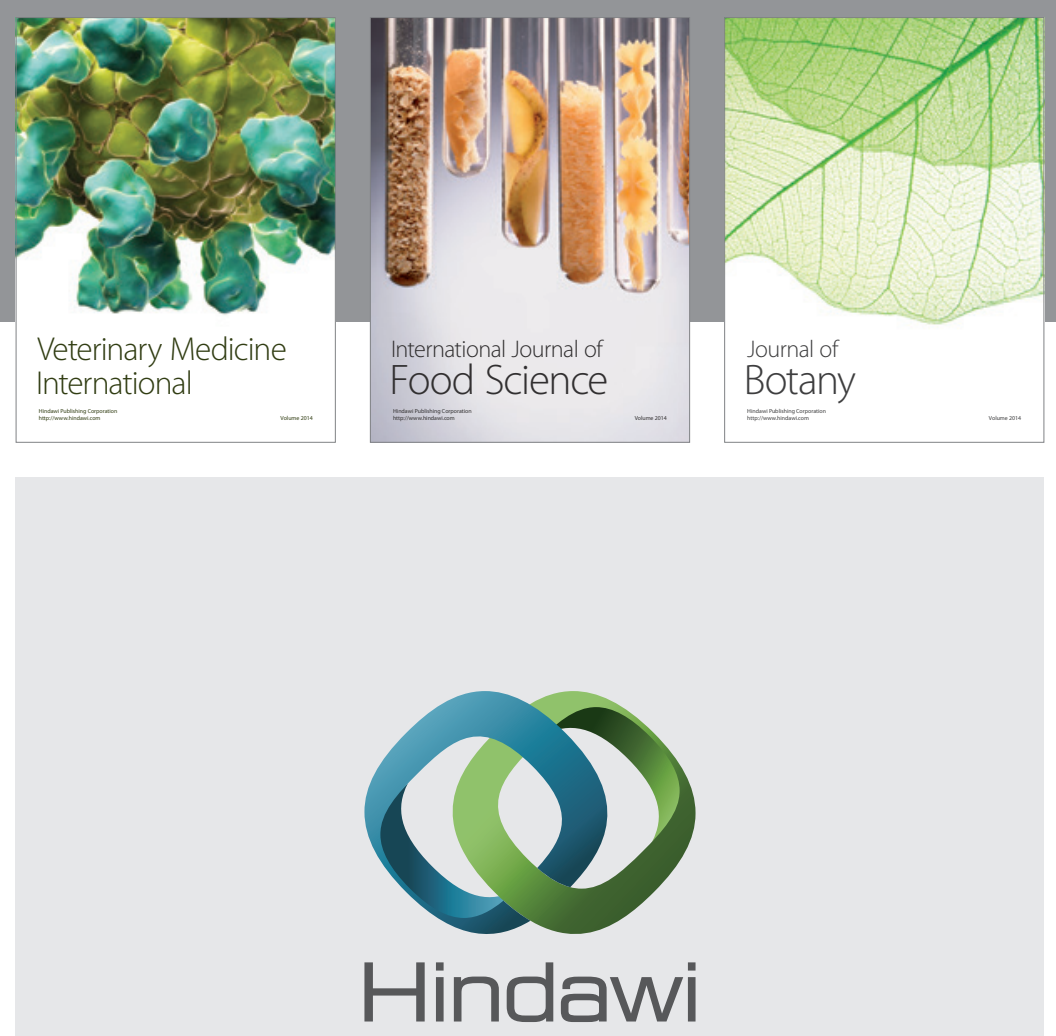

Submit your manuscripts at

http://www.hindawi.com
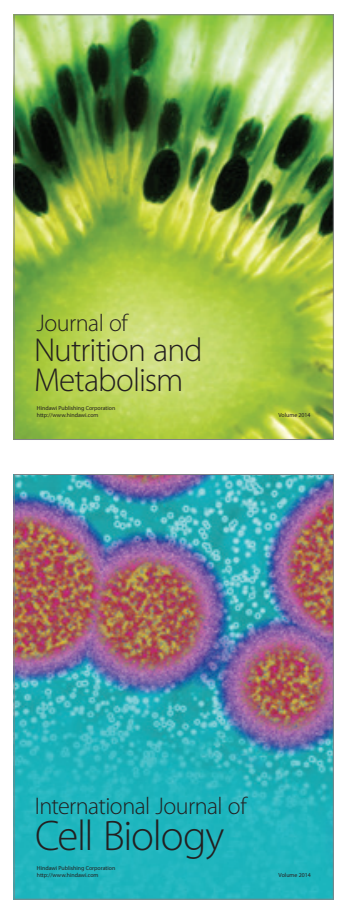
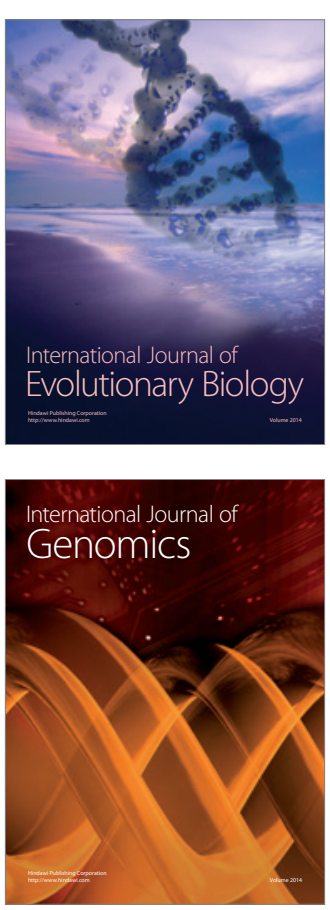
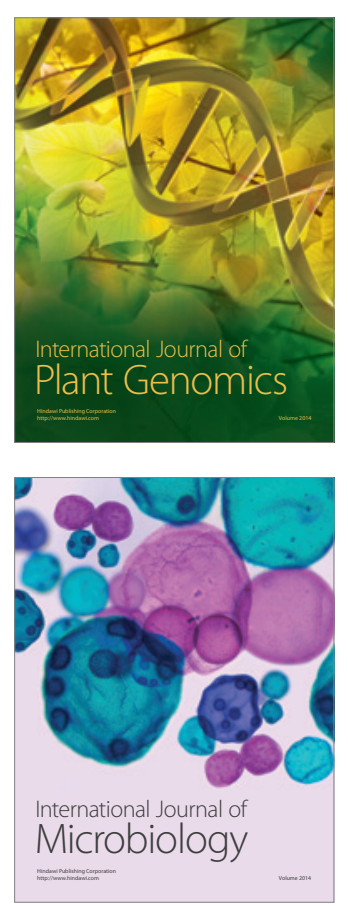

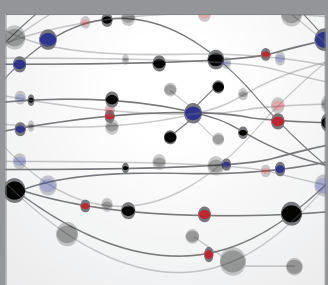

The Scientific World Journal
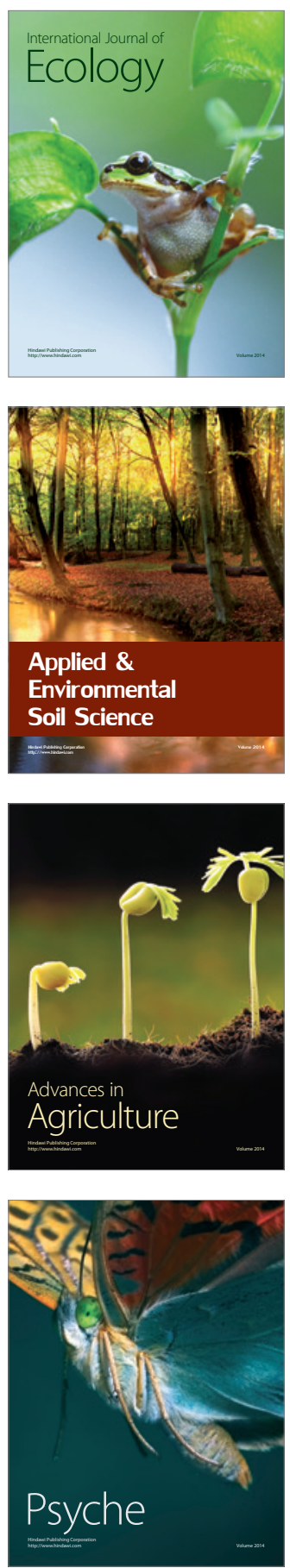